Article

\title{
Investigation on the Effects of Internal EGR by Variable Exhaust Valve Actuation with Post Injection on Auto-ignited Combustion and Emission Performance
}

\author{
Insu Cho ${ }^{1}$, Yumin Lee ${ }^{2}$ and Jinwook Lee ${ }^{3, *}$ \\ 1 Department of Mechanical Engineering, Graduate School, Soongsil University, Seoul 06978, Korea; \\ chois@soongsil.ac.kr \\ 2 Department of Mechanical Engineering, Undergraduate Course, Soongsil University, Seoul 06978, Korea; \\ lym6350@naver.com \\ 3 Department of Mechanical Engineering, Soongsil University, Seoul 06978, Korea \\ * Correspondence: immanuel@ssu.ac.kr; Tel.: +82-2-820-0929
}

Received: 19 February 2018; Accepted: 9 April 2018; Published: 10 April 2018

\begin{abstract}
Variable valve mechanisms are usually applied to a gasoline combustion engine to improve its power performance by controlling the amount of intake air according to the operating load. These mechanisms offer one possibility of resolving the conflict of objectives between a further reduction of raw emissions and an improvement in fuel efficiency. In recent years, variable valve control systems have become extremely important in the diesel combustion engine. Importantly, it has been shown that there are several potential benefits of applying variable valve timing (VVT) to a compression ignition engine. Valve train variability could offer one option to achieve the reduction goals of engine-out emissions and fuel consumption. The aim of this study was to investigate the effects on part load combustion and emission performance of internal exhaust gas recirculation (EGR) by variable exhaust valve lift actuation using a cam-in-cam system, which is an electronically variable valve device with a variable inside cam retarded to about 30 degrees. Numerical simulation based on GT-POWER has been performed to predict the $\mathrm{NO}_{\mathrm{x}}$ reduction strategy at the part load operating point of $1200 \mathrm{rpm}$ in a four-valve diesel engine. A GT-POWER model of a common-rail direct injection engine with internal EGR was built and verified with experimental data. As a result, large potential for reducing $\mathrm{NO}_{\mathrm{x}}$ emissions through the use of exhaust valve control has been identified. Namely, it is possible to utilize heat efficiently as recompression of retarded post injection with downscaled specification of the exhaust valve rather than the intake valve, even if the CIC V1 condition with a reduction of the exhaust valve has a higher internal EGR rate of about $2 \%$ compared to that of the CIC V2 condition.
\end{abstract}

Keywords: variable exhaust valve actuation; recompression; internal EGR; GT-POWER

\section{Introduction}

In diesel engines, a robust compression-ignited combustion strongly depends on the cylinder charge temperature, composition, and cylinder pressure during valve train events [1]. Variable valve actuation (VVA) technology refers to a technique or combination of technologies that changes valve timing, valve duration, and valve lift, etc., depending on operating conditions and operating strategies, instead of opening and closing intake and exhaust valves with a single, fixed-cam profile. Especially, the compression ignition engine shows the required characteristics of the variable valve system which 
can control the opening period of the valve. These VVA mechanisms have limited valve lift and timing control, depending on the shape of the mechanism and method in which it is operated.

Therefore, it is desirable to design the variable valve operating mechanism in which the ability to control the range of the valve lifting and opening timing is set during the development stage of the actual technology [2].

There are several potential benefits of applying variable valve control to a diesel engine: Optimization of the charge motion, a reduced in-cylinder temperature, and pumping work only if there is no swirl valve, leading to better low-speed performance. Namely, the adoption of the variable valve in a compression ignition engine enables control of the temperature of exhaust gas and effective control of the compression ratio through intake or exhaust air quantity.

Based on these functional characteristics, a variable valve system is expected to be essential as a core technology for improving the combustion of diesel engines. The output of the compression ignition engine is affected by the fuel injection system, volume efficiency, friction loss, and pumping loss, etc. Volumetric efficiency depends on the combustion chamber geometry, engine speed, and the timing and lift of valve opening and closing. Therefore, increasing the volumetric efficiency and reducing the loss caused by friction and pumping for the maximum output according to each operating condition improves the power performance. During this optimization process, the optimum intake and exhaust flow rate and timing are adjusted according to the operating conditions without lowering the torque stability and the maximum output [3]. For instance, early exhaust valve opening (EEVO) and cylinder deactivation are implemented to raise the exhaust gas temperatures for DOC activation [4].

In a variable valve strategy known to be effective in controlling the cylinder charge temperature and composition, various exhaust valve mechanisms have been designed to control exhaust gas recirculation (EGR). The term EGR usually refers to a deliberate, external process, but there is also a level of internal EGR. This occurs when the residual combustion gas in the cylinder at the end of the exhaust stroke is mixed with the incoming charge. There is, therefore, a proportion of internal EGR which must be taken into account when planning EGR strategies. Scavenging efficiency will vary with engine load, and in an engine fitted with variable valve timing, a further parameter must be considered.

Mirko B. et al. found that internal EGR has a greater potential than external EGR to realize an accurate control of the EGR rate and $\mathrm{NO}_{\mathrm{x}}$ emission in transient operation [5]. Also, it was found that applying internal EGR moderated combustion by delaying the ignition timing, thereby suppressing in-cylinder pressure oscillations [6]. VVA for automotive diesel engines enables the pre-heating of the exhaust system to be accelerated by the effect of internal EGR [7].

Gonzalez D. et al. presented a comprehensive scheme to obtain higher exhaust gas temperatures. Internal EGR can be combined with multiple injections after the main injection event, thereby altering the heat release rate and the exothermic reactions in the exhaust stroke [8].

Furthermore, the work of Guan, W. demonstrated that the combination of the EGR and Miller cycle strategies can lead to minimum impact on the smoke emission and fuel economy, while achieving lower engine-out $\mathrm{NO}_{\mathrm{x}}$ emissions and a higher exhaust gas temperature for an efficient exhaust after treatment systems [9].

Kai D. et al. tested several VVT variants (exhaust cam phasing, late intake valve opening, Miller, second exhaust event, cylinder deactivation) as promising heating strategies. These heating strategies are finally compared to conventional heating measures to demonstrate their potentials in terms of faster after-treatment light-off with increased conversion efficiencies and benefits in $\mathrm{CO}_{2}$ emissions [10].

In this study, exhaust recompression valve strategies are discussed in light of GT-POWER, 1D cycle simulation model results for a common-rail direct injection single-cylinder engine with internal EGR by using VVA and post fuel injection having an effect on the results [11]. So, the aim of this study is to improve part load fuel economy and emissions. 


\section{Numerical Model Description}

\subsection{Engine Modeling}

In this study, the GT-POWER program (Gamma Technologies, Westmont, IL, USA) was used to predict the reduction of $\mathrm{NO}_{\mathrm{x}}$ at partial engine load under the engine speed of $1200 \mathrm{rpm}$, as shown in Table 1. Cam-in-cam, the variable valve scheme used in this study, is an electronically variable valve device, and the inside of the variable cam is retarded to about 30 degrees. An extensive GT-POWER model of the base R-engine with internal EGR created by variable exhaust valve actuation was built in this study.

Table 1. Operating points on map in R-engine.

\begin{tabular}{cc}
\hline Low Load & Low, Middle Load \\
Fuel Injection Quantity: $12 \mathrm{mg}$ & Fuel Injection Quantity: 12 \& $19.8 \mathrm{mg}$ \\
\hline Idle + Low Speed & Middle Speed \\
Engine speed: $800 \mathrm{rpm}$ & Engine speed: 1200 2000 rpm \\
\hline
\end{tabular}

Among the five points on the operation map of the R-engine, as shown in Figure 1a, the standard value (hereinafter referred to as "Base" case) is selected when the engine of the basic cam follows the injection strategy according to the operating map. Figure $1 \mathrm{~b}$ shows the prototype cam-in-cam system used in this study and variable valve profile.

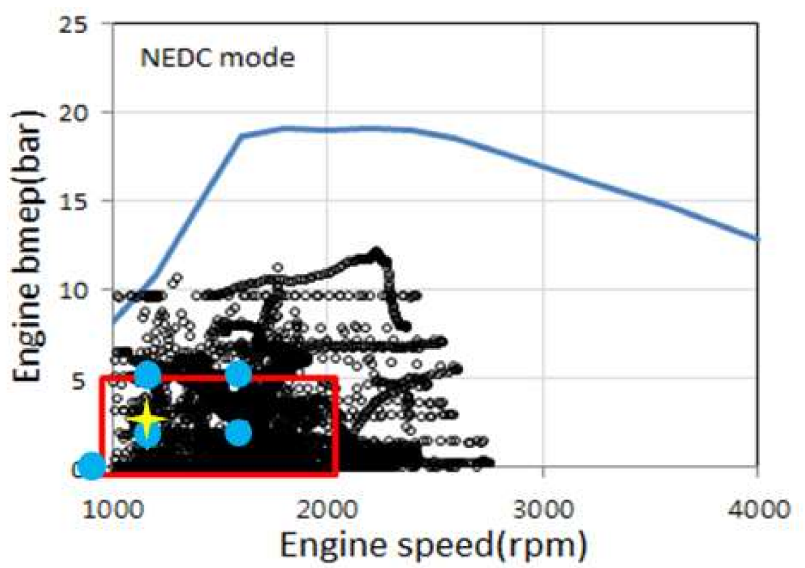

(a)

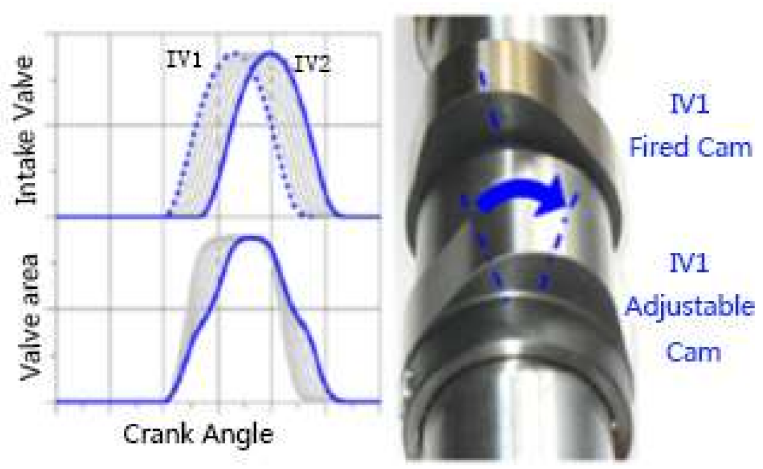

(b)

Figure 1. Engine map and variable valve device. (a) Five operating points on map in R-engine; (b) Prototype cam-in-cam system (MAHLE). 
Commercial R-engine has 4-cylinder and 4-valve per cylinder. Cylinder pressure was measured at 1-cylinder only for combustion analysis. Engine crank shaft connected with a DC dynamometer and high-pressure fuel injected in the cylinder by signal of injection device. Table 2 shows specification of R-engine used in this study.

Table 2. Specification of R-engine used in this study.

\begin{tabular}{cccc}
\hline Item & Unit & \multicolumn{2}{c}{ Specification } \\
\hline Bore x Stroke & $\mathrm{mm}$ & \multicolumn{2}{c}{$88 \times 90$} \\
Displacement & $\mathrm{cc}$ & \multicolumn{2}{c}{499} \\
Valve per cylinder & - & $4(2$ intake and 2 exhaust $)$ \\
Compression ration & - & \multicolumn{2}{c}{16} \\
\hline Intake valve & CAD & IVO & bTDC 10 \\
& IVC & aBDC 28 \\
\hline Exhaust valve & CAD & EVO & bBDC 54 \\
& & EVC & aTDC 4 \\
\hline
\end{tabular}

The GT-POWER program is a commercial engine analysis program widely used as an industry standard for vehicle and powertrain simulation software. It is a next-generation integrated CAE application that is becoming increasingly important in the industry due to its functions for engine evaluation, such as cooling system operations, as well as fuel consumption, noise, etc. under an arbitrary driving condition. It provides a fast solver for 1D and 3D simulations, making realistic simulations of large-scale systems possible. It also has the advantage of containing detailed information on valves, cylinders, and combustion behavior (predictive or data-based functions) for engine combustion calculations. The numerical full-circuit model developed by this study consists of the engine part (single cylinder, valves, pipes, etc.), valve train part (cam, camshaft, valve rod, etc.), and fuel injection part (piezo actuator, nozzle, rod, needle, orifice, etc.). The valve part in the engine system has received a valve profile from rotating the cam by the valve train model linked with the engine model. The injector model is built up with internal construction of a third piezo injector and linked with an engine model. The engine combustion model uses DIPULSE because $\mathrm{NO}_{\mathrm{x}}$ prediction is possible with improved accuracy. The heat transfer model uses WoschniGT.

The fuel injection model was designed with a third piezo injector and verified through comparing experimental injection data obtained by the Bosch-tube method. The Bosch-tube measurement principle is to feed the fuel into the pipe with a cross-sectional area A and select the fuel control volume in the pipe flowing at the speed of sound as $\mathrm{c}$ when the fuel in the pipe moves at a speed of $\mathrm{u}$. By knowing the sonic velocity and fuel density in the pipe and determining the amount of change in pressure in the chamber, the injection rate can be calculated [12].

\subsection{Four Variable Valve Train Configurations}

Four different variants, as shown in Table 3, stood out as candidates for simulation testing: (1) "Base" case, for comparing with other cases; (2) CIC V1 for a recompression strategy that reduced valve lifting and duration; (3) CIC V2 for recompression that reduced valve lifting and duration about the exhaust valve; and (4) CIC V3 for added post fuel injection based on CIC V2, as shown in Table 3. With the exhaust recompression valve strategy, the cylinder charge temperature is controlled by trapping the hot exhaust gas from the previous engine cycle. This is done by closing the exhaust valve early during the exhaust stroke while opening the intake valve late in relation to the exhaust valve closing timing. The crank-angle period when both intake and exhaust valves are closed around the engine top dead center (TDC) is defined as the negative valve overlap (NVO). 
Table 3. Four variable valve train configurations.

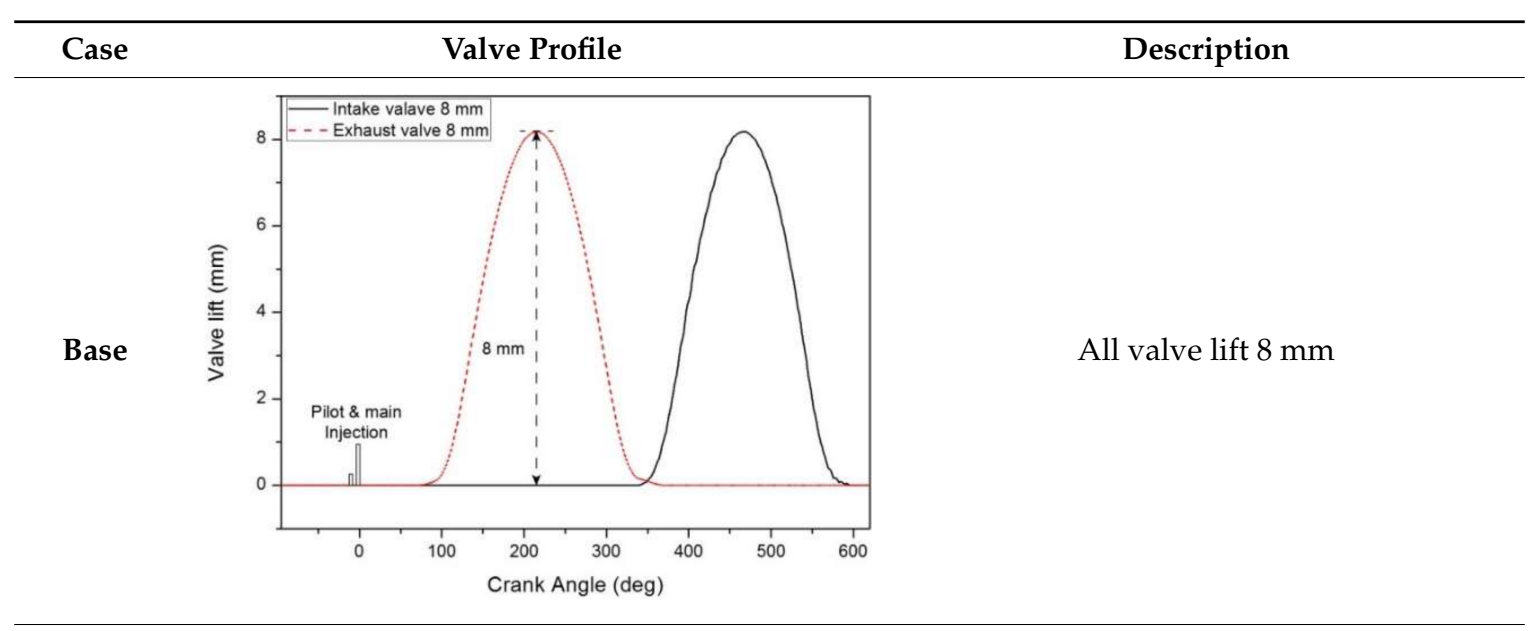
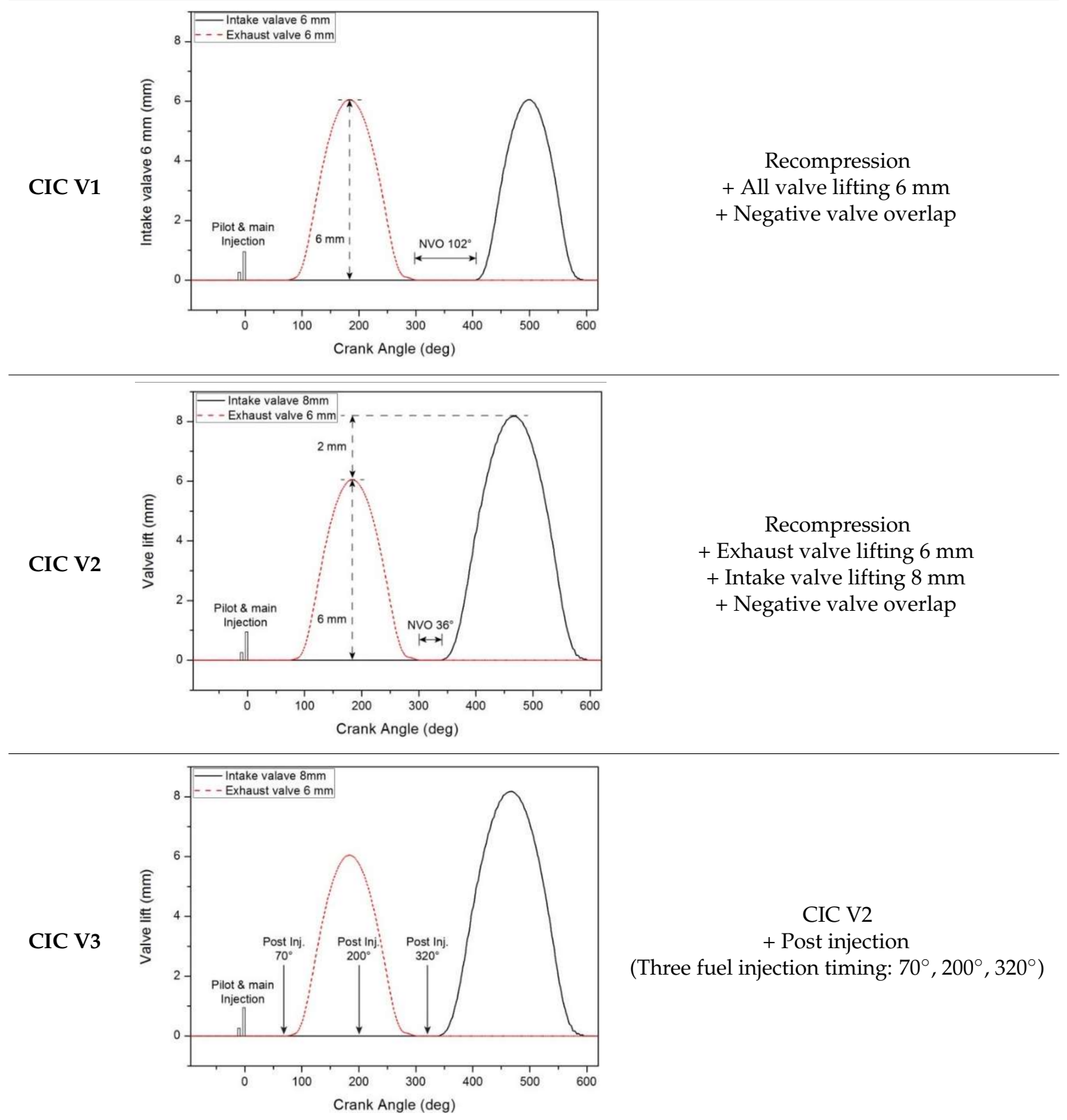

CIC V2

+ Post injection

(Three fuel injection timing: $70^{\circ}, 200^{\circ}, 320^{\circ}$ ) 
Figure 2 shows the schematic diagram of this analysis process. In order to study the effects of internal EGR by variable exhaust valve actuation, a methodology was first developed to investigate recompression internal EGR, wherein a variable exhaust valve timing mechanism is used to transfer exhaust gas from one cycle to the next, just as in the valve strategies referred to as "Base" case, CIC V1, and CIC V2. The additional step in the process begins with CIC V2 as normal and then adds three different timings of post fuel injection.

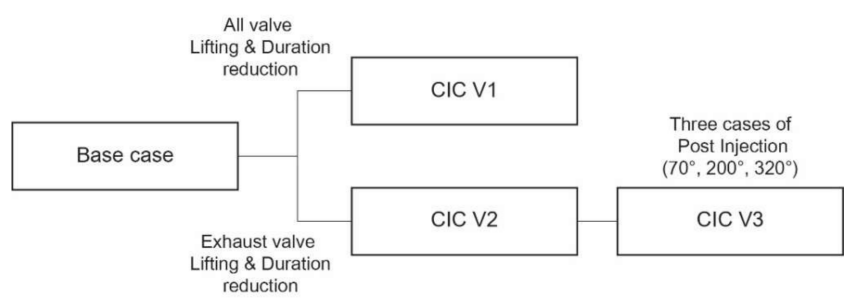

Figure 2. Schematic diagram of this numerical analysis process.

\subsection{Model Verification}

In order to improve the model's predictive accuracy, the engine model was developed in the 1D GT-POWER and compared with the combustion pressure and heat release of in-cylinder gas. Tables 4 and 5 show the engine operating condition in the experiment and fuel injection condition, respectively. Figure 3 shows the result of the model correlation under the test condition in Table 4. Model validation took place once the engine dynamometer data were available. It was shown that the experimental results indeed agreed with the combustion analysis.

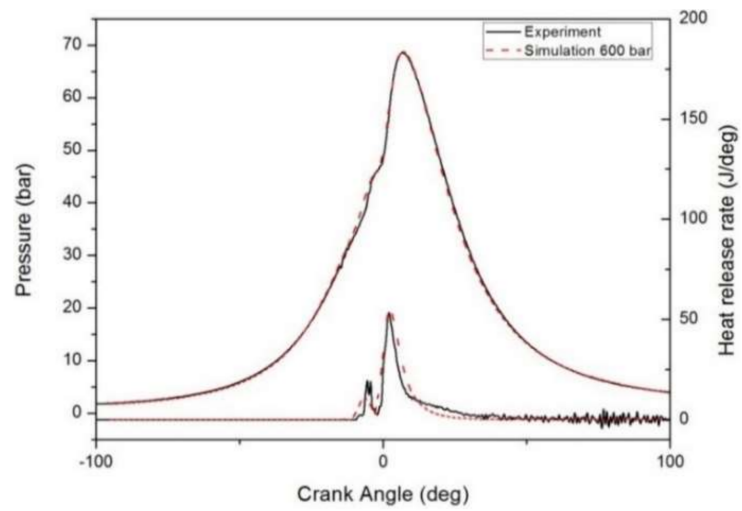

(a)

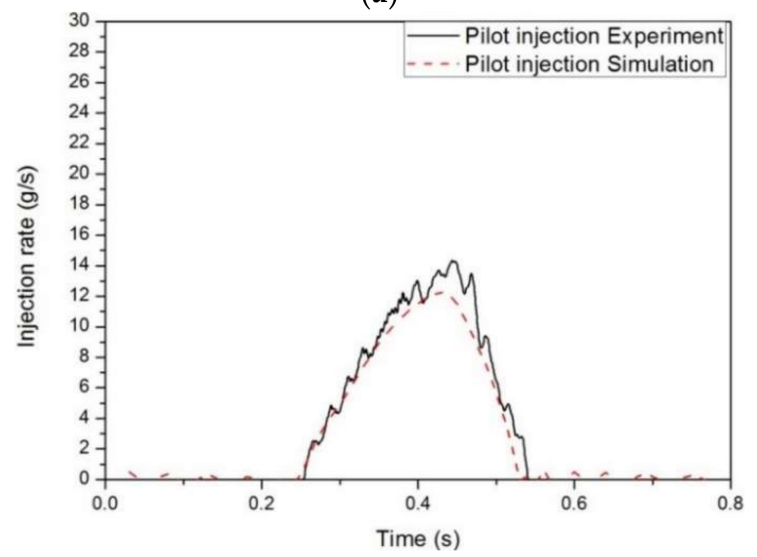

(b)

Figure 3. Cont. 


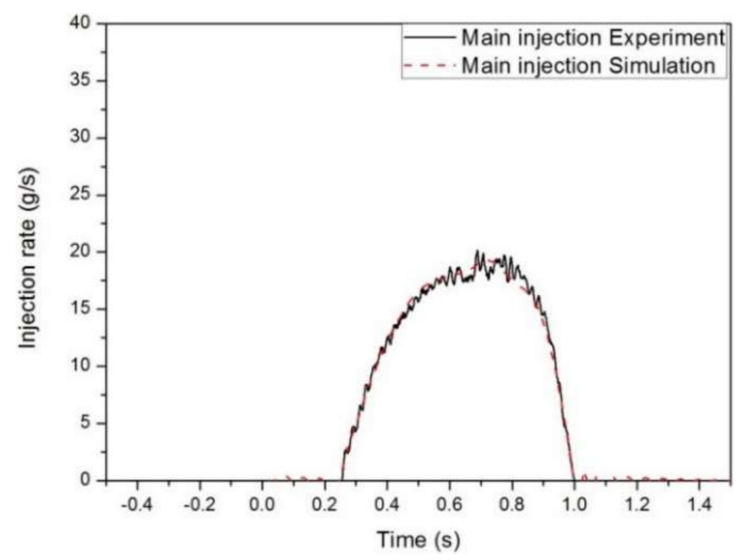

(c)

Figure 3. Predictive model correlation with experiment data. (a) Pressure and Heat Release Rate; (b) Pilot injection rate; (c) Main injection rate.

Table 4. Engine operating condition.

\begin{tabular}{cc}
\hline Item & Specification \\
\hline Engine speed (rpm) & 1200 \\
Fuel injection quantity (mg) & 12 \\
Fuel injection pressure (bar) & 600 \\
Intake \& Exhaust valve lift (mm) & 8 \\
\hline
\end{tabular}

Table 5. Fuel injection condition.

\begin{tabular}{ccc}
\hline Injection & Pilot & Main \\
\hline Fuel injection timing $(\mathrm{deg})$ & 15 ATDC & 5 ATDC \\
Fuel injection quantity $(\mathrm{mg})$ & 1.4 & 11.1 \\
\hline
\end{tabular}

\section{Results and Discussion}

\subsection{Combustion Characteristic of Recompression Internal EGR}

Figure 4 shows the temperature traces for three different recompression strategies: "Base" case, CIC V1, and CIC V2. In the recompression cases (CIC V1, CIC V2), the engine operates at a higher temperature than the "Base" case. The result is that there is a limited flow of fresh air and burned gas due to negative overlap. CIC V1 is less effective in enhancing the cylinder temperature than CIC V2, due to its relative larger intake valve lift and duration than in the exhaust valve. The maximum temperature in the case of CIC V2 is higher during the main combustion period.

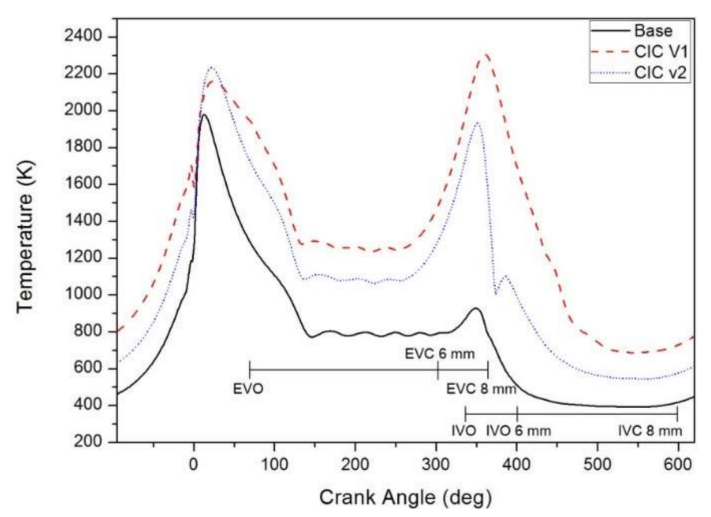

Figure 4. Temperature variation for different recompression strategies. 
Figure 5 shows the intake flow variation for three different recompression strategies. In the case of CIC V2, there was a rapid back flow of burned gas through the intake valve. This comes from an increased flow rate through the intake valve above that of CIC V1. Additionally, the burned gas discharged to the intake valve, and the temperature of the in-cylinder gas dropped. At a crank angle of $470^{\circ}$, hereafter fresh air is flowing into the cylinder and then the temperature of the trapped gas is increased. Therefore, it can be concluded that back flow in the valves is one of the main factors creating combustion performance.

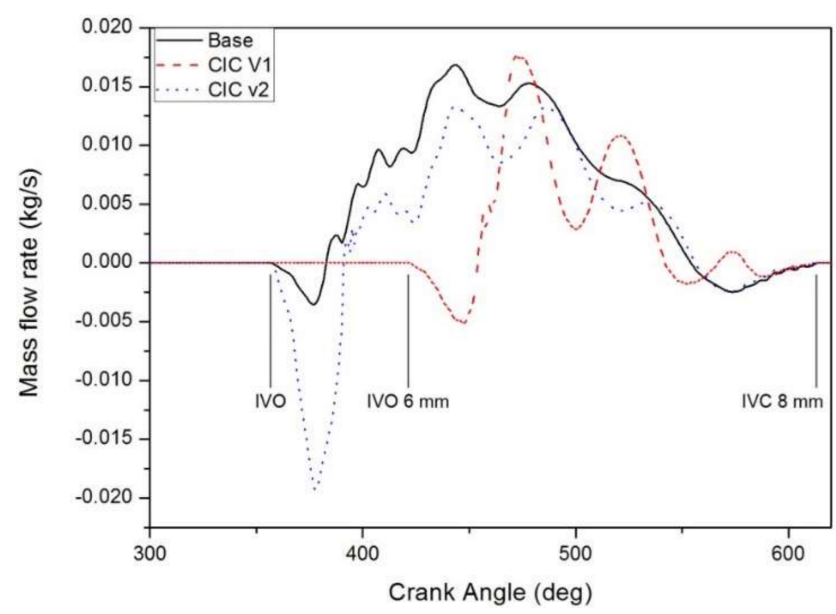

Figure 5. Flow traces at intake valve for different recompression strategies.

Figure 6 shows the total trapped mass traces for different recompression strategies: "Base" case, CIC V1, and CIC V2. Total trapped mass can be defined as the quantity of all chemical species (including air, fuel, EGR, residual gas, etc.) in the cylinder at the start of the cycle. In the recompression condition, the total trapped mass is reduced and the amount of the trapped mass in the case of CIC V2 is relatively more elevated before combustion, due to the increase in the intake valve lift and duration. In the case of CIC V2, when the intake valve is open at $350^{\circ}$, the mass quantity drops rapidly, and the negative valve overlap creates the high temperature and causes burned gas to only flow back through the intake valve at TDC.

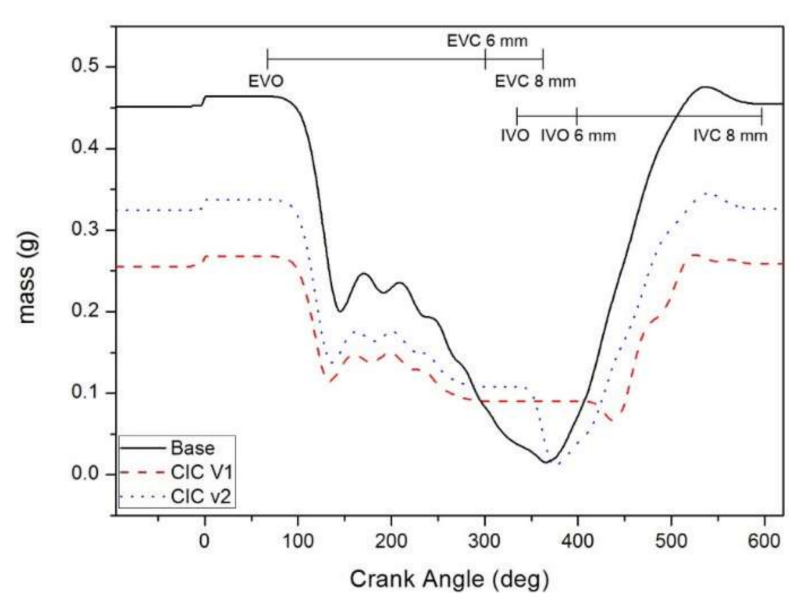

Figure 6. Total trapped mass traces for three different recompression strategies.

As shown in Figure 7, the increase in in-cylinder pressure during the negative valve overlap indicates its oxidation by the recompression of trapped gas. However, the in-cylinder temperature and combustion pressure in CIC V1 and CIC V2 are lower than in the "Base" case, due to a decrease in 
fresh air at the next ignition. This result showed that the exchange of gas was more enhanced in the case of CIC V2 because of the decreased combustion pressure in the period and peak value than the CIC V1 case during the intake stroke.

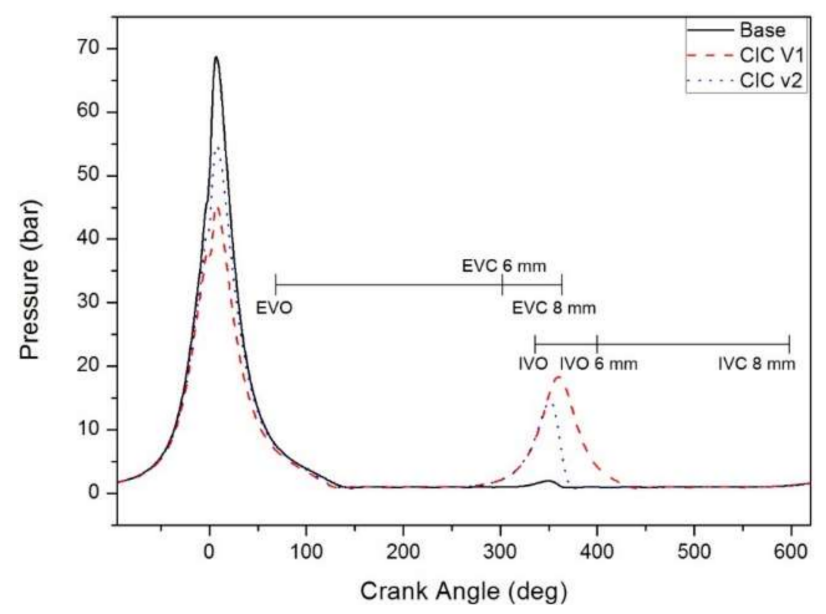

Figure 7. Pressure variation for three different recompression strategies.

Figure 8 shows the pressure-volume (PV) cycle for three different recompression cases. The main feature of this diagram is that the amount of energy expended or received by the system as work can be estimated as the area under the curve in the figure. In the cases of CIC V1, its pumping loss has no area on the graph due to the very low volume efficiency during the intake stroke. It indicates a higher peak pressure than the case of CIC V2. As can be seen, increased inflow of fresh air to the cylinder of CIC V2 causes pumping loss, but the maximum pumping pressure is lower than in the case of CIC V1.

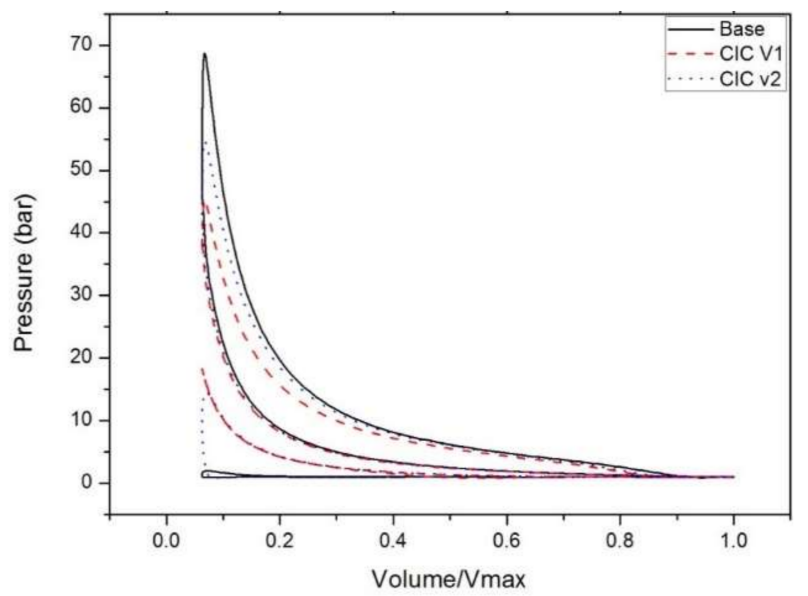

Figure 8. P-V diagram for three different recompression strategies.

Figure 9 shows that a decreased pressure and inflow of fresh air affects the increase in the ignition delay at the pilot injection of high-pressure fuel. Then, a decreased heat release rate and expanded diffusion combustion at main injection occur as changes in the cases of CIC V1 and V2, as characteristics of low temperature combustion. 


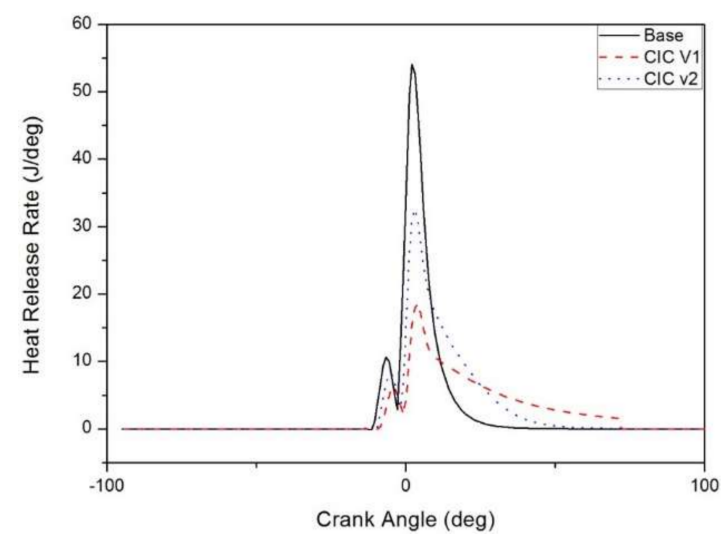

Figure 9. Heat Release Rate traces for three different recompression strategies.

\subsection{Effect of Post Fuel Injection in Recompression Internal EGR}

By adjusting the internal EGR applied by variable exhaust valve actuation, a great volume of heat energy occurred and was generally wasted, but it can be used to achieve lower emissions, activation of the after-treatment system, and stable operation of low temperature combustion. This study investigated the possibility of VVA that involved post fuel injection for improving thermal efficiency in the three cases. The points of post injection started (1) at $70^{\circ}$ containing a maximum quantity according to the total trapped mass; (2) at $200^{\circ}$, with both the lowest pressure and temperature and the ending of the back flow through the exhaust valve during the recompression process; and (3) at $320^{\circ}$, with the raising of pressure and temperature by closed intake and the exhaust valve during the recompressing process. Furthermore, the quantity of post fuel injection was set to $20 \%$ of the total fuel mass in both the pilot and main injection periods. As a reference, the specific cutoff point for which the second injection is small enough relative to the main injection to constitute a post injection, rather than a generic split injection, is not well defined, but a maximum of approximately $20 \%$ of the total fuel in the post injection is consistent with most existing self-described post-injection studies [13]. Figure 10 is the result of the temperature traces for different recompression strategies with post injection. Post injection at $70^{\circ}$ in the exhaust stroke caused an increase in temperature. In the case of post injection at $320^{\circ}$, it was decremented that a high temperature occurred by potential heat, which is the decreasing of temperature during NVO, which then affects gas exchange efficiently. Additionally, post injection at $320^{\circ}$ was performed under conditions that included a lower burning mass than in other cases, so it showed the highest effect by potential heat. Figure 11 shows the result of the total trapped mass traces for different recompression strategies with post injection. In the case of post injection at $320^{\circ}$, it shows a higher variation in trapped mass, due to its internal gas flow activity with a high temperature.

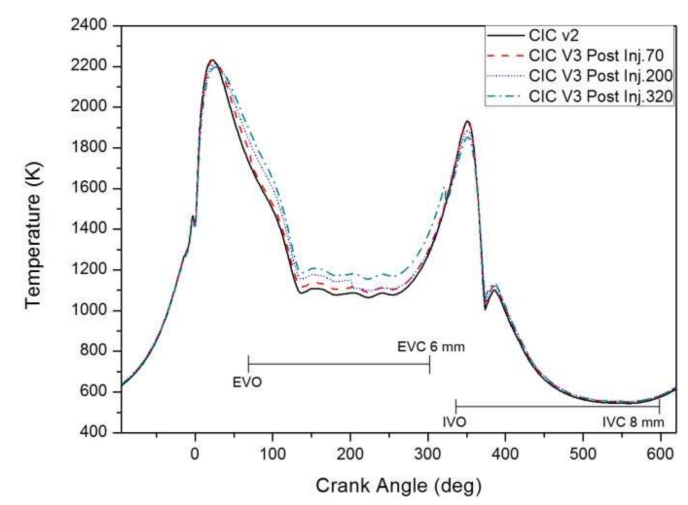

Figure 10. Temperature variation for different recompression strategies with three post injections. 


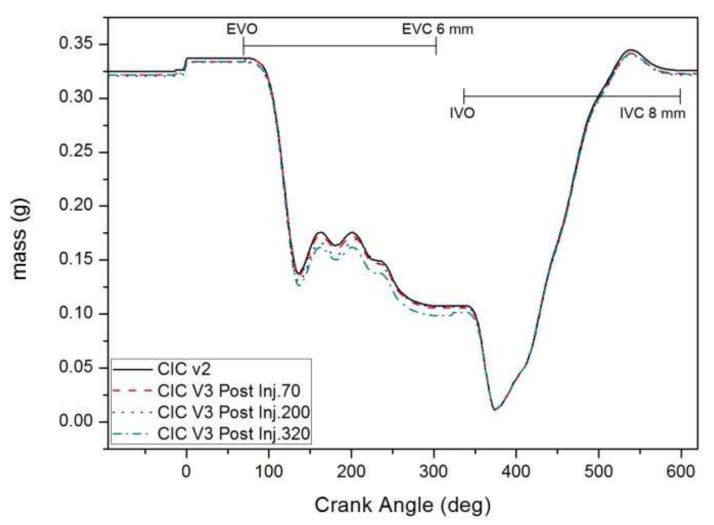

Figure 11. Total trapped mass traces for different recompression strategies with three post injections.

Figure 12 shows the result of the heat release rate traces for different recompression strategies with post injection. It shows the highest heat release at the pilot and main injection points in the case of post injection at $320^{\circ}$. This is caused by increasing the burnt fuel with post injection by decreasing the total trapped mass. In addition, it can be concluded that post injection is one of the main factors influencing thermal efficiency increased by a diffusion combustion area.

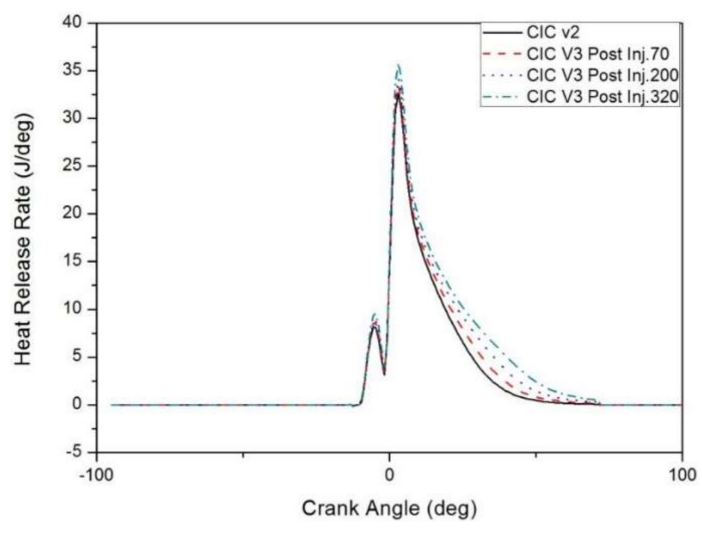

Figure 12. Heat release rate traces for different recompression strategies with three post injections.

Figure 13 shows the result of in-cylinder pressure variation for different recompression strategies with post injection. In the case of post injection at $320^{\circ}$, it shows the lowest pressure that results from reducing the pressure rate at the point of main combustion by increasing the gas exchange.

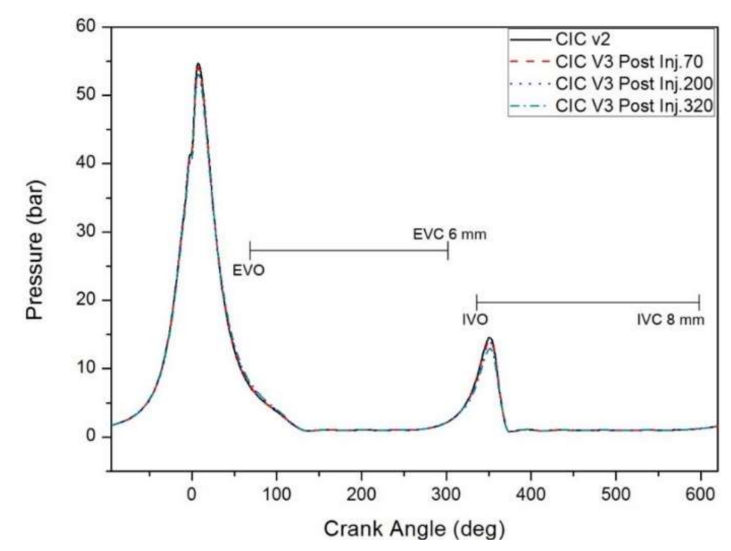

Figure 13. Pressure variation for different recompression strategies with three post injections. 


\subsection{Comparison of Emission Performance}

Figure 14 shows comparisons of $\mathrm{NO}_{\mathrm{x}}$ emission for different variable valve control strategies. It was found that the CIC V1 case, with no-full lift and duration of intake and exhaust valve, shows the lowest $\mathrm{NO}_{\mathrm{x}}$ emission with minimum temperature, due to using recompression internal EGR. If it is difficult to control both valves, as shown in Figure 14, the CIC V3 case, with no-full lift and duration of exhaust valve only and post injection, is an effective strategy to reduce $\mathrm{NO}_{\mathrm{x}}$ emission at part load operating conditions in a compression ignition combustion. In the case of post injection at $320^{\circ}$ in $\mathrm{CIC}$ $\mathrm{V} 3$, it shows the lowest $\mathrm{NO}_{\mathrm{x}}$ emission under variable exhaust valve control without a variable intake valve. As shown in Figure 15, the lowest volume efficiency occurred in the case of CIC V1 with full control of both the intake and exhaust valve. Whereas, it was found that CIC V2 and CIC V3 have a similar volume efficiency at each maximum combustion temperature.

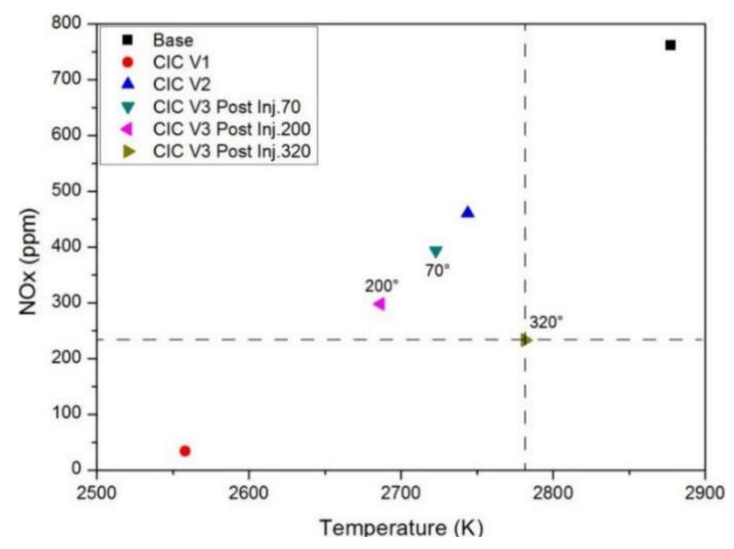

Figure 14. Comparison on $\mathrm{NO}_{\mathrm{x}}$ emission for different variable valve control strategies.

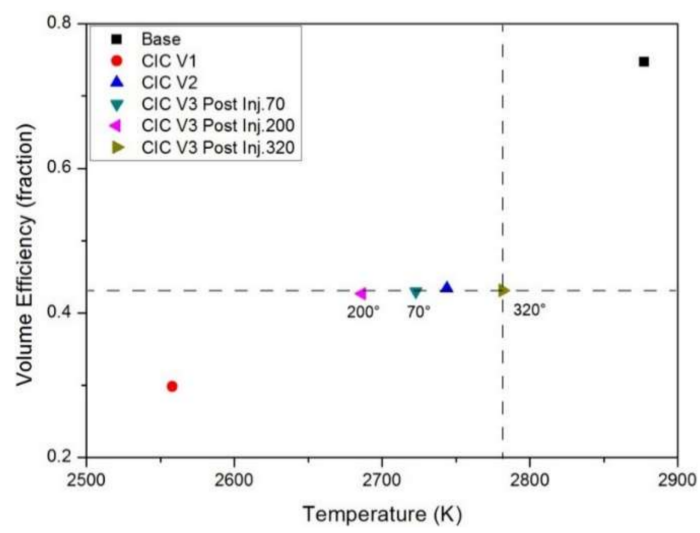

Figure 15. Comparison on volume efficiency for different variable valve control strategies.

Figure 16 shows the comparison results for $\mathrm{NO}_{x}$ emission versus indicated mean effective pressure (IMEP) for all variable valve control strategies applied in this study. This shows a noticeable reduction in $\mathrm{NO}_{\mathrm{x}}$ emission with a reduction in IMEP. Especially, CIC V1 is a moderate case with regard to emission reduction, but this strategy was worse with regard to thermal energy. As the post injection timing in CIC V3 was retarded, it caused a decrease of $\mathrm{NO}_{x}$ and an increase in IMEP linearly. The result was derived from effective work due to increased burnt fuel through post fuel injection. Figure 17 shows the comparison result for $\mathrm{NO}_{x}$ emission versus indicated specific fuel consumption (ISFC) for all variable valve control strategies. This shows that the lowest fuel consumption with $\mathrm{NO}_{\mathrm{x}}$ emission was in the case of CIC V1. Furthermore, the post injection at $320^{\circ}$ in CIC V3 is the best case with regard to the level of $\mathrm{NO}_{x}$ emission under fuel penalty. Figure 18 shows the comparison of the internal EGR 
rate for different variable valve control strategies. The internal EGR rate is defined as a ratio between the total volume of the cylinder and the total trapped mass, with the exception of trapped air, before the beginning of combustion. It shows a difference of about $10 \%$ between the "Base" case and the recompression case. This EGR strategy is made possible by the design of valve control (lift, phase, timing, etc.), which allows for more burned gas to be trapped, without the use of any additional device for external EGR. Figure 19 shows the comparison of $\mathrm{NO}_{\mathrm{x}}$ reduction by applying different variable valve control strategies. Recompression strategy, as a bypass process to avoid the $\mathrm{NO}_{\mathrm{x}}$ emission zone in compression ignition, is beneficial to the heat release rate and volumetric efficiency at the design speed, and it also reduces $\mathrm{NO}_{x}$ emission.

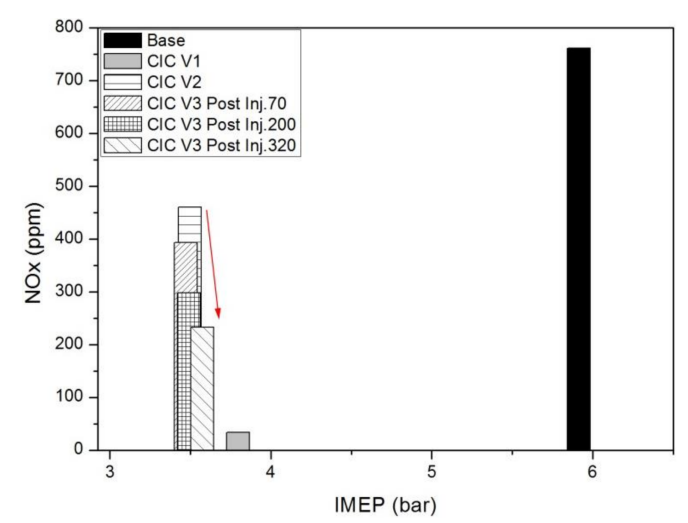

Figure 16. Comparison on IMEP versus $\mathrm{NO}_{\mathrm{x}}$ for different variable valve control strategies.

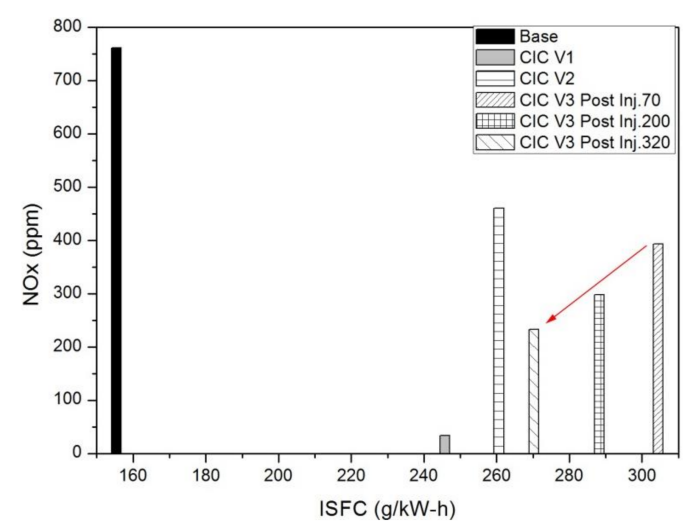

Figure 17. Comparison on ISFC versus $\mathrm{NO}_{\mathrm{x}}$ for different variable valve control strategies.

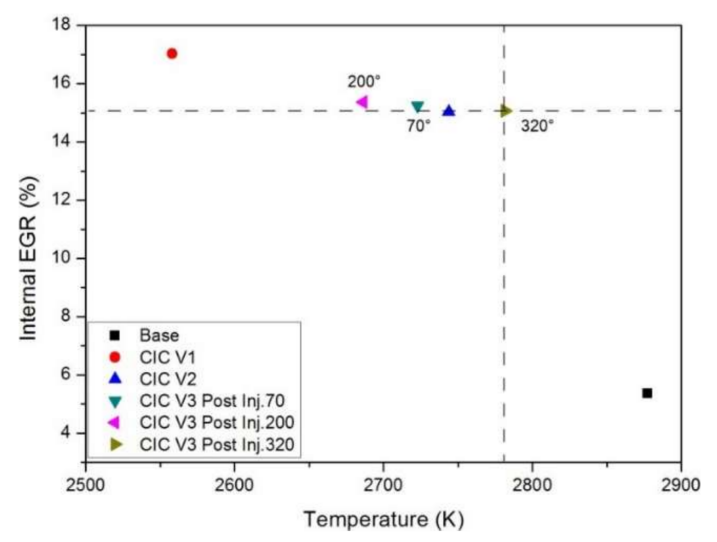

Figure 18. Comparison of internal EGR rate for different variable valve control strategies. 


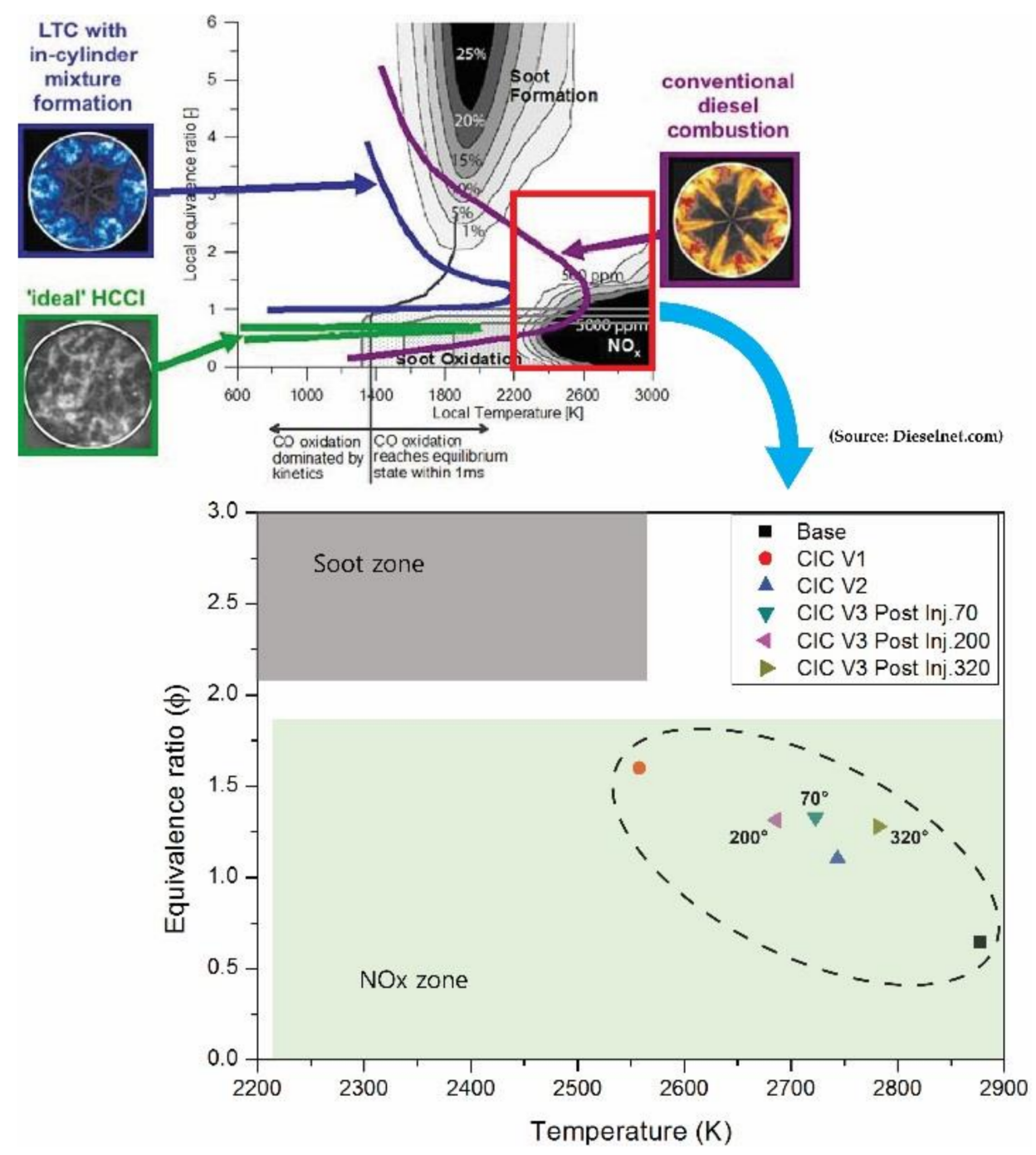

Figure 19. Comparison on $\mathrm{NO}_{\mathrm{x}}$ reduction by applying different variable valve control strategies.

\section{Conclusions}

In this study, the effect of internal EGR by variable valve actuation with post injection using a full-circuit GT-POWER model verified by experimental data was investigated to predict auto-ignited combustion performance that includes in-cylinder pressure and temperature, heat release, ISFC, IMEP, and $\mathrm{NO}_{x}$ emission. Conclusions obtained by this study can be summarized as follows:

(1) Recompression internal EGR leads to negative valve overlap effects and a higher temperature in engine operation, due to its trapping of burnt gas and limited air flow, creating a high temperature inside the cylinder. The earlier the exhaust valve closes during the exhaust stroke, as in the case of a larger NVO, the greater the amount of the hot exhaust gas from the previous engine cycle would be trapped in the cylinder. This leaves less room in the cylinder for the in-coming fresh air mass, thereby increasing the cylinder charge temperature while decreasing the oxygen level in the cylinder charge. As a result, there is an optimal setting of NVO for each operating condition to achieve the best engine performance.

(2) The CIC V2 case is used for enhancing the internal EGR rate, which is reduced in both the lifting and duration of the exhaust valve without control of the intake valve, thus the operating temperature is decreased overall, but a higher temperature is seen at the main combustion period than in the "Base" and CIC V1 cases. This is caused by the inflow of more fresh air while keeping 
internal gas in the cylinder and increasing the discharging of burnt gas through the intake valve. Therefore, effective work has risen due to a pressure drop in the intake stroke and the rising of pressure at the main combustion, compared with the CIC V1 case.

(3) For the use of thermal energy wasted when adjusting recompression by variable valve actuation, post injection with three cases was applied with total injected fuel of $20 \%$ based on CIC V2. Each post injection shows a similar volume efficiency, but retarded post injection timing caused an increase in IMEP, as well as a reduction of both ISFC and $\mathrm{NO}_{\mathrm{x}}$. In the case of post injection at $320^{\circ}$, when increasing the pressure and temperature for both intake and exhaust valves, which were closed in the recompression period, the highest engine operating temperature was seen, but there were lower emissions of $\mathrm{NO}_{\mathrm{x}}$ than in other post injection cases.

(4) The recompression internal EGR is effective in utilizing heat energy by enhancing the EGR rate by about $10 \%$. Additionally, recompression with retarded post injection is beneficial to IMEP with $\mathrm{NO}_{\mathrm{x}}$ reduction, even if $\mathrm{CIC} \mathrm{V} 1$ with no-full lift and duration of the intake and exhaust valve has an internal EGR rate of about $2 \%$ higher than that of CIC V2 with no-full lift and duration of the exhaust valve.

(5) Finally, the internal EGR scheme with variable exhaust valve actuation in a diesel engine is advantageous to apply post injection from the viewpoint of utilizing thermal energy. However, since the ISFC increases according to post-injection conditions, it is necessary to consider the maximum use of exhaust heat energy for $\mathrm{NO}_{\mathrm{x}}$ reduction.

Acknowledgments: This research was supported by the R\&D project on Industrial Core Technology (2017) of MOTIE (Ministry of Trade, Industry and Energy) in Republic of Korea.

Author Contributions: Insu Cho, Yumin Lee and Jinwook Lee conceived and designed the numerical analysis; Insu Cho and Yumin Lee produced analytic model and performed the simulation; Insu Cho and Jinwook Lee analyzed the data and wrote the paper; Jinwook Lee supervised and advised all parts in this paper.

Conflicts of Interest: The authors declare no conflicts of interest.

\section{References}

1. Johnson, T.V. Review of Vehicular Emissions Trends. SAE Int. J. Engines 2015, 8, 1152-1167. [CrossRef]

2. Tran, T.H.T.; Enomoto, H.; Nishioka, K.; Simizu, K. Development of Small Gasoline Engine with Electronic Variable Valve Timing Unit; SAE Technical Paper 2011-32-0579; SAE International: Warrendale, PA, USA, 2011.

3. Johnson, T.; Joshi, A. Review of Vehicle Engine Efficiency and Emissions; SAE Technical Paper 2017-01-0907; SAE International: Warrendale, PA, USA, 2017.

4. Bharath, A.N.; Yang, Y.; Reitz, R.D.; Rutland, C. Comparison of Variable Valve Actuation, Cylinder Deactivation and Injection Strategies for Low-Load RCCI Operation of a Light Duty Engine; SAE International 2015-01-0843; SAE International: Warrendale, PA, USA, 2015.

5. Baratta, M.; Finesso, R.; Misul, D.; Spessa, E. Comparison between Internal and External EGR Performance on a Heavy Duty Diesel Engine by Means of a Refined 1D Fluid-Dynamic Engine Model; SAE International 2015-24-2389; SAE International: Warrendale, PA, USA, 2015.

6. Shimada, T.; Yoshida, Y.; Rin, C.; Yamada, M.; Ito, N.; Iijima, A.; Yoshida, K.; Shoji, H. Influence of Internal EGR on Knocking in an HCCI Engine. In Proceedings of the JSAE/SAE 2015 Small Engine Technologies Conference, Osaka, Japan, 17-19 November 2015.

7. Piano, A.; Millo, F.; Di Nunno, D.; Gallone, A. Numerical Analysis on the Potential of Different Variable Valve Actuation Strategies on a Light Duty Diesel Engine for Improving Exhaust System Warm Up; SAE Technical Paper 2017-24-0024; SAE International: Warrendale, PA, USA, 2017.

8. Gonzalez, D.M.; Di Nunno, D. Internal Exhaust Gas Recirculation for Efficiency and Emissions in a 4-Cylinder Diesel Engine; SAE Technical Paper 2016-01-2184; SAE International: Warrendale, PA, USA, 2016.

9. Guan, W.; Pedrozo, V.; Zhao, H.; Ban, Z.; Lin, T. Investigation of EGR and Miller Cycle for $\mathrm{NO}_{x}$ Emissions and Exhaust Temperature Control of a Heavy-Duty Diesel Engine; SAE Technical Paper 2017-01-2227; SAE International: Warrendale, PA, USA, 2017. 
10. Deppenkemper, K.; Özyalcin, C.; Ehrly, M.; Pischinger, S. 1D engine simulation approach for optimizing engine and exhaust aftertreatment thermal management for passenger car diesel engines by means of variable valve train (VVT) applications. In Proceedings of the 2018 SAE World Congress Experience Conference, Detroit, MI, USA, 10-12 April 2018.

11. Martin, J.; Sun, C.; Boehman, A.; O'Connor, J. Experimental Study of Post Injection Scheduling for Soot Reduction in a Light-Duty Turbodiesel Engine; SAE Technical Paper 2016-01-0726; SAE International: Warrendale, PA, USA, 2016.

12. Han, S.; Kim, J.; Lee, J. A Study on the Optimal Actuation Structure Design of a Direct Needle-Driven Piezo Injector for a CRDi Engine. Appl. Sci. 2017, 7, 320. [CrossRef]

13. O'Connor, J.; Musculus, M. Post Injections for Soot Reduction in Diesel Engines: A Review of Current Understanding; 2013 SAE International 2013-01-0917; SAE International: Warrendale, PA, USA, 2013.

(c) 2018 by the authors. Licensee MDPI, Basel, Switzerland. This article is an open access article distributed under the terms and conditions of the Creative Commons Attribution (CC BY) license (http://creativecommons.org/licenses/by/4.0/). 